\title{
The Warrens and other pioneering clinician pathologists of the Massachusetts General Hospital during its early years: an appreciation on the 200th anniversary of the hospital founding
}

\author{
Robert H Young and David N Louis
}

The James Homer Wright Pathology Laboratories of the Massachusetts General Hospital, Harvard Medical School, Boston, MA, USA

\begin{abstract}
To celebrate the bicentennial of the 1811 charter to establish the Massachusetts General Hospital, we tell the stories of the physicians and surgeons of the hospital who practiced pathology until the discipline was more firmly established with the recruitment of James Homer Wright who became the first full-time pathologist at the hospital in 1896. One of the two co-founders of the hospital, John Collins Warren (famed primarily for being the surgeon at the first public demonstration of ether anesthesia) had a major interest in pathology; he published a book focused on gross pathology (1837) and began the important specimen collection subsequently known as the Warren Anatomical Museum at Harvard Medical School (HMS). An early physician, John Barnard Swett Jackson, became the first professor of pathology in the United States (1847) and was a noted collector whose specimens were added to the Warren Museum. Dr Jackson showed no interest in microscopy when it became available, but microscopy was promoted from circa the late 1840s at Harvard and likely at the hospital by Oliver Wendell Holmes, the famed essayist who was on the staff of the hospital and faculty at the medical school. Microscopy was probably first used at the Hospital with any frequency on examination of fluids by the first officially designated 'Microscopist,' John Bacon Jr, in 1851, and after the mid-1850s by Calvin Ellis on anatomic specimens; Ellis went on to pioneering reform of the HMS curriculum. Reginald Heber Fitz succeeded Ellis in 1871 and was the first to be officially designated as 'Pathologist' at the hospital. Fitz is remembered for two major contributions: his paper showing the nature of, and potential surgical cure for, the disease that he termed 'appendicitis'; and his description of acute pancreatitis. With the microscope now firmly entrenched and with the increase in surgery after Fitz's work on appendicitis, surgical pathology grew quickly. J Collins Warren, the grandson of the co-founder, had a major interest in pathology and in 1895 published an impressive volume entitled 'Surgical Pathology and Therapeutics.' Dr Warren had a major interest in breast disease and was a pioneer of needle biopsy in the evaluation of breast masses. In 1888, William Fiske Whitney joined the staff of the hospital and spent his nearly 30 -year career practicing primarily as a surgical pathologist, making particular innovations in intraoperative consultation. The contributions of these individuals brought the field from a gross pathology-oriented discipline mostly oriented around teaching to a microscopy-dependent practice integral to patient care, and hence set the stage for the formal founding of the Pathology department in 1896.

Modern Pathology (2011) 24, 1285-1294; doi:10.1038/modpathol.2011.132; published online 16 September 2011
\end{abstract}

Keywords: John Collins Warren; JBS Jackson; Oliver Wendell Holmes; John Bacon; Calvin Ellis; Reginald Heber Fitz; J Collins Warren; William Fiske Whitney

Correspondence: RH Young, MD, James Homer Wright Pathology Laboratories of the Massachusetts General Hospital, Harvard Medical School, Warren 2, 55 Fruit Street, Boston, MA 02114, USA.

E-mail: rhyoung@partners.org

Received 15 June 2011; revised 20 July 2011; accepted 25 July 2011; published online 16 September 2011
This year marks the 200th anniversary of the granting of the charter for the establishment of the Massachusetts General Hospital (MGH) (Figure 1). In commemoration of this anniversary, we have edited a book ${ }^{1}$ telling the story of pathology at the hospital from its founding until today. As with many historical endeavors, it has uncovered much 


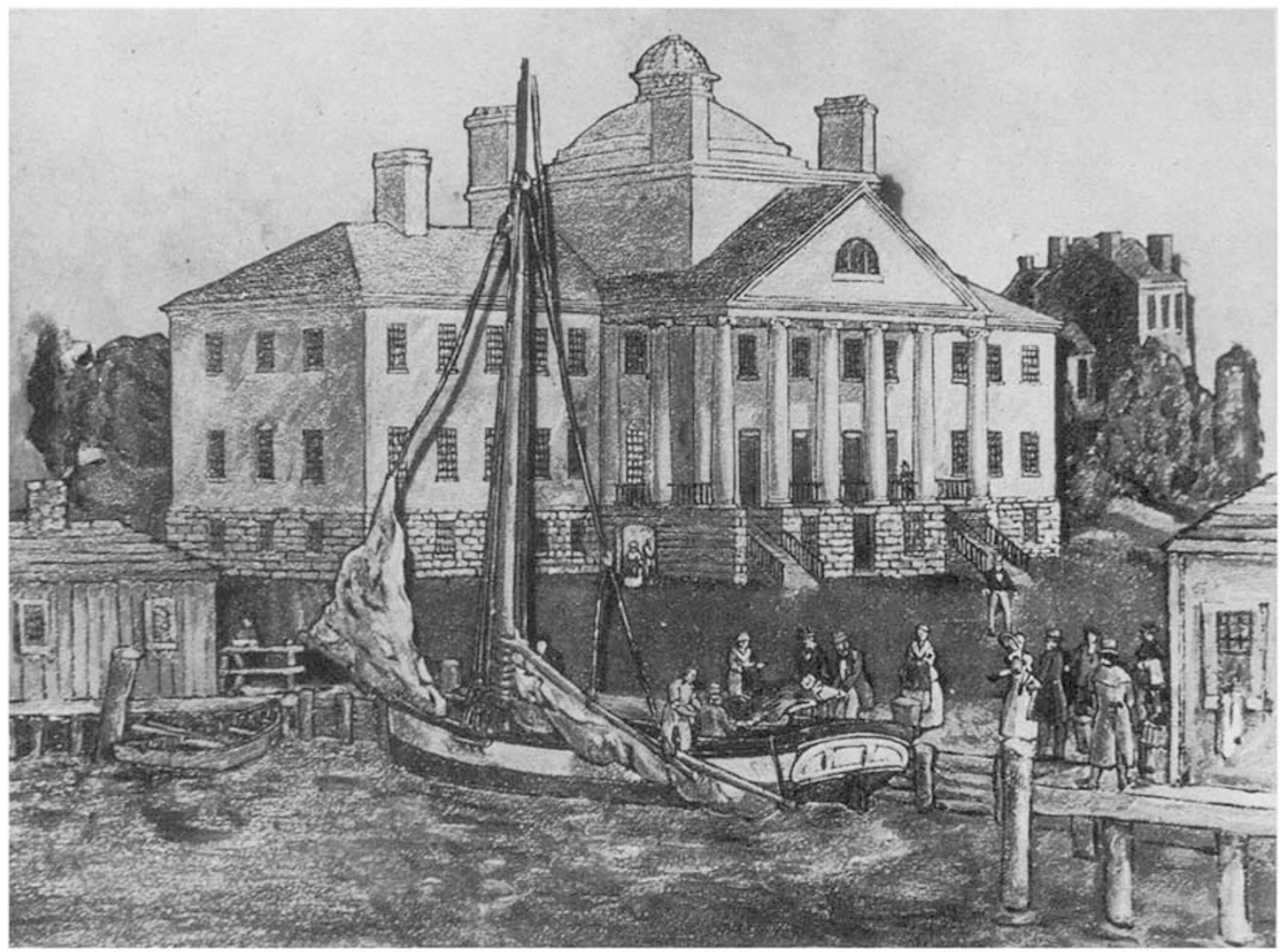

Bringing Patients to Massachusetts General Hospital in 1821

Figure 1 Sketch of Bulfinch Building showing proximity to Charles River at the time the hospital admitted its first patient.

information about notable persons whose contributions deserve to be better remembered. We were well aware of the contributions of James Homer Wright, ${ }^{2}$ the first 'full-time' pathologist at the hospital, appointed in 1896. Based on earlier work by Dr Robert E Scully and the late Dr Austin L Vickery $\mathrm{Jr}^{3}$ we also knew that pathology had been conducted at the hospital prior to the arrival of Dr Wright by a number of physicians and surgeons. However, our appreciation of their contributions was heightened considerably the more we read about them and we realized that most pathologists, even at our own hospital, were not aware of the extent of their contributions to pathology. In aggregate they solidified the importance of gross pathology, had a significant role in the early application of microscopic pathology, demonstrated the role of pathology in patient care, showed how pathology was central to clinical discoveries and also were active in using gross and microscopic specimens for medical student education (Table 1). Those considered herein laid a solid foundation for the development of anatomic pathology in the hospitals of Harvard Medical School (HMS) and their influence on the development of the field extended well beyond New England.

The origin of the MGH can be traced to the humanitarian motivations of a local clergyman, the Reverend John Bartlett, who was the Chaplain of the Almshouse in Boston from 1807 to 1811. His concern for the condition of the patients there prompted him to plan to develop an asylum in the city. His endeavor gathered steam when he invited the two most influential physicians in the city, Dr John Collins Warren and Dr James Jackson, to a meeting with other eminent citizens, including John Adams and John Quincy Adams, on March 8 1810. Drs Warren and Jackson expanded the plans of Reverend Bartlett to include a general hospital and, on 20 August 1810, circulated a letter appealing for funds to establish one. The hospital charter was granted the next year. However, the poor economy related to the War of 1812 delayed progress and the cornerstone of the initial hospital, the Bulfinch Building, was not laid until 4 July 1818. The hospital opened in 1821. More detailed discussion of the early days of the hospital can be found in the recent bicentennial book on the history of the MGH. ${ }^{4}$

The relationship of the MGH to HMS in the years encompassed by this essay changed. In the early years of the medical school at Harvard, students received relatively informal training on the Harvard College campus in Cambridge. The medical school moved from Cambridge to Boston in 1810. Then, after the MGH opened for patients in 1821 it was, until the opening of Boston City Hospital in 1864, the only hospital associated with the medical school. In 1847, HMS moved to North Grove Street, directly adjacent to the MGH (Figure 2), where it 
Table 1 Early clinician pathologists of the Massachusetts General Hospital and their major roles and contributions

John Collins Warren

One of the two founders of the MGH

Publications on gross pathology

First public demonstration of ether anesthesia

Began the collection that became the Warren Anatomical

Museum

John Barnard Swett Jackson

First professor of Pathology in the United States

Developed Warren Anatomical Museum, serving as first curator

Oliver Wendell Holmes

Popularized the use of the microscope at HMS

May have influenced the purchase of the first microscope at the MGH

Drew attention to the contagious nature of puerperal fever

John Bacon Jr

First Microscopist and Chemist at MGH

Calvin Ellis

First MGH physician to use the microscope to evaluate

anatomical specimens

Reginald Heber Fitz

First officially designated 'Pathologist' at the MGH

Characterized and named 'appendicitis' and encouraged its surgical treatment

Wrote seminal paper on acute pancreatitis

J Collins Warren

Began recording of microscopic diagnoses in patient records at MGH

Demonstrated use of biopsy needle and biopsies for patient management

Use of the term 'surgical pathology' (in the title of a textbook) Early work with frozen sections

William Fiske Whitney

First officially designated 'Surgical Pathologist' at the MGH First full-time anatomical pathologist

Active in intraoperative pathology consultation

Abbreviations: HMS, Harvard Medical School; MGH, Massachusetts General Hospital. remained until 1883. When HMS was located on North Grove Street, the Pathology Department at the medical school and the MGH were likely essentially the same, even though there was a tiny room designated a 'laboratory' on the ground floor of the Bulfinch Building (Figure 3).

\section{The beginnings of pathology at the MGH and HMS: John Collins Warren and JBS Jackson}

John Collins Warren (Figure 4) was a member of a distinguished New England family ${ }^{5}$ dating back to one of the earliest English settlers of the region. A tradition of medicine in the Warren family had been established by Dr Warren's father, also John Warren, and grandfather, Dr Joseph Warren, the latter being killed in the Battle of Bunker Hill. Dr Warren's father was one of the founders of HMS in 1782 and the first Professor of Anatomy and Surgery of HMS. He authored the first paper published in the Boston Medical and Surgical Journal (now the New England Journal of Medicine), which was on cardiac disease and included speculation on the pathological basis of the diseases he discussed.

John Collins Warren graduated from HMS in 1797, and studied medicine at Guy's Hospital, London (with Astley Cooper) and later in Edinburgh and Paris (with Dupuytren and Corvisart among others), before returning to Boston after 3 years abroad. He brought anatomical specimens back with him and continually added them to his collection thereafter, based on materials obtained from the many operations he performed as the first surgeon at the MGH. These were added to specimens his father had collected and in 1847 when the HMS building on North Grove Street near the MGH was completed, he donated the collection to the school. The Harvard Corporation stated that 'the collection of anatomical specimens now presented by Dr Warren to the President and fellows, should be known and designated as the Warren Anatomical Museum.'

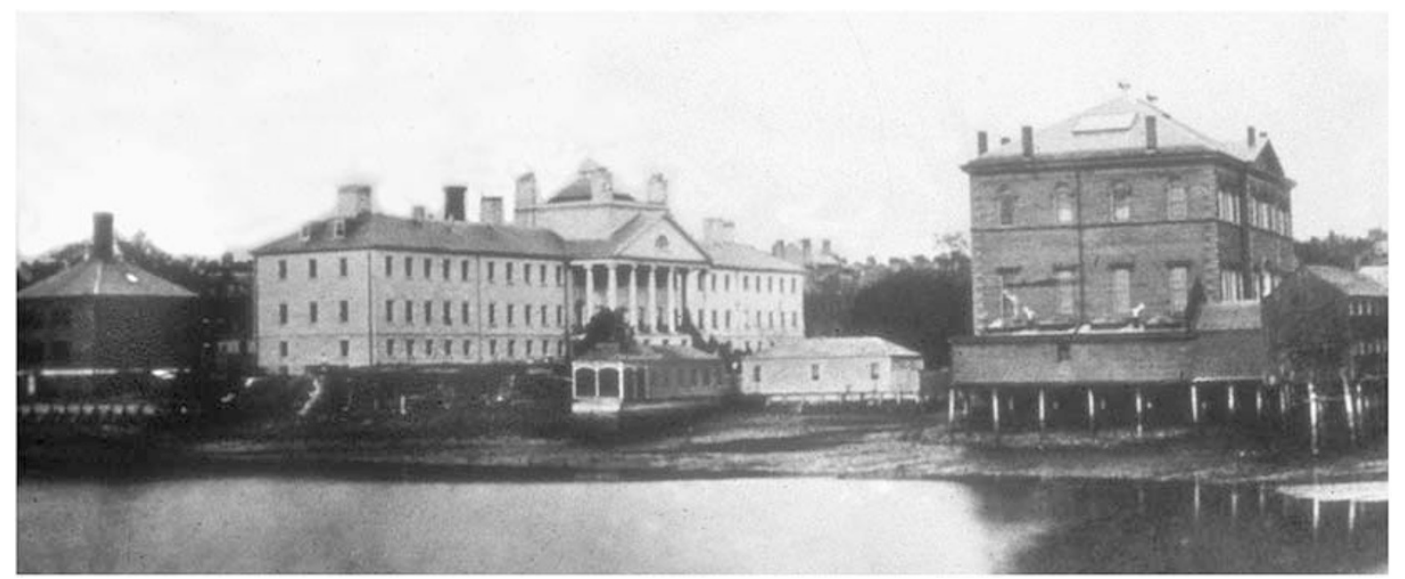

Figure 2 The Bulfinch Building (left) and the adjacent Harvard Medical School on North Grove Street, 1853. The Charles River is in the foreground. 


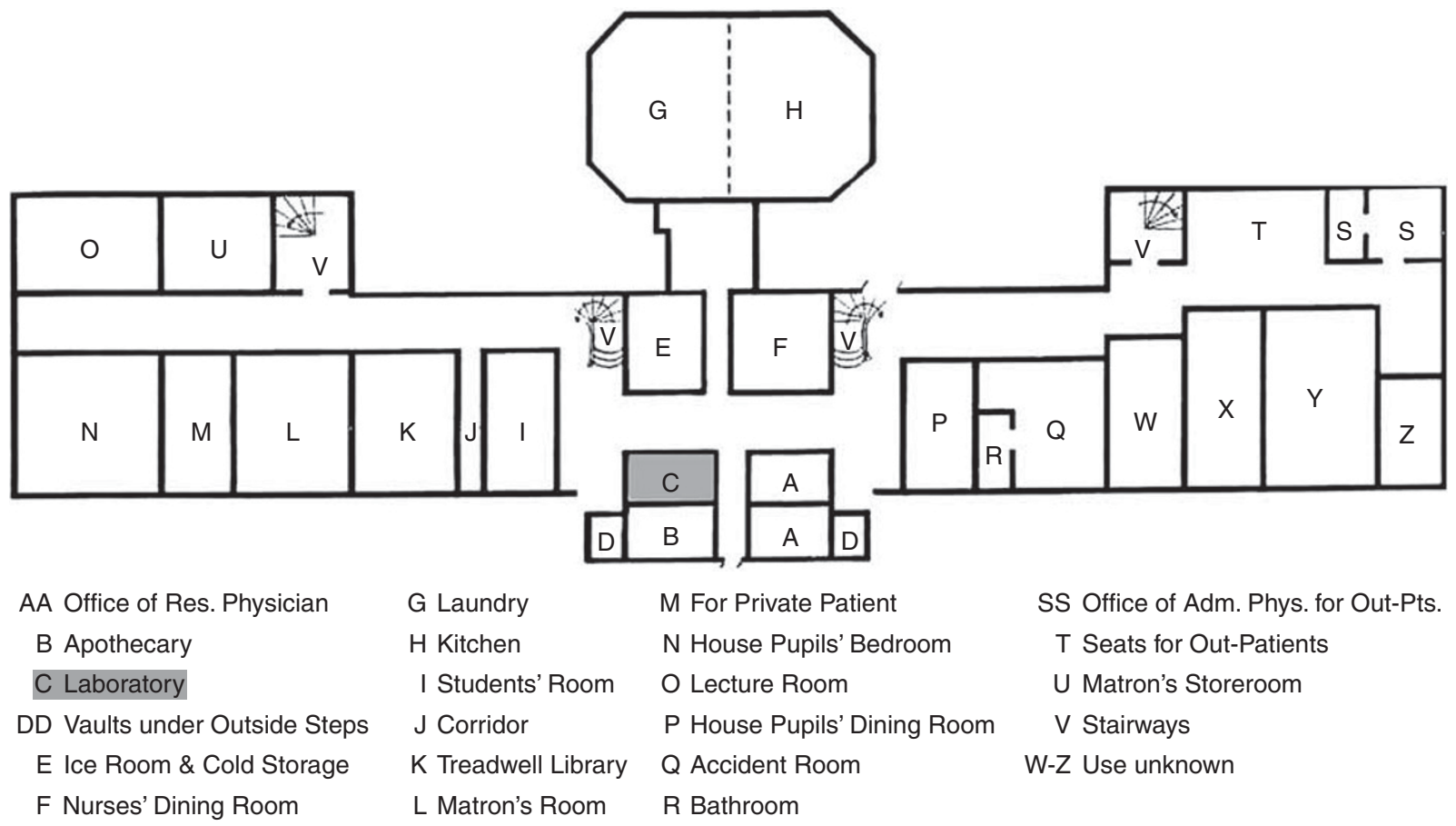

Plan of Ground Floor of Bulfinch Building in 1872 (As accurate as possible at this date, 1928)

Figure 3 Bulfinch Building floor plan, 1872, with the laboratory (C) highlighted.
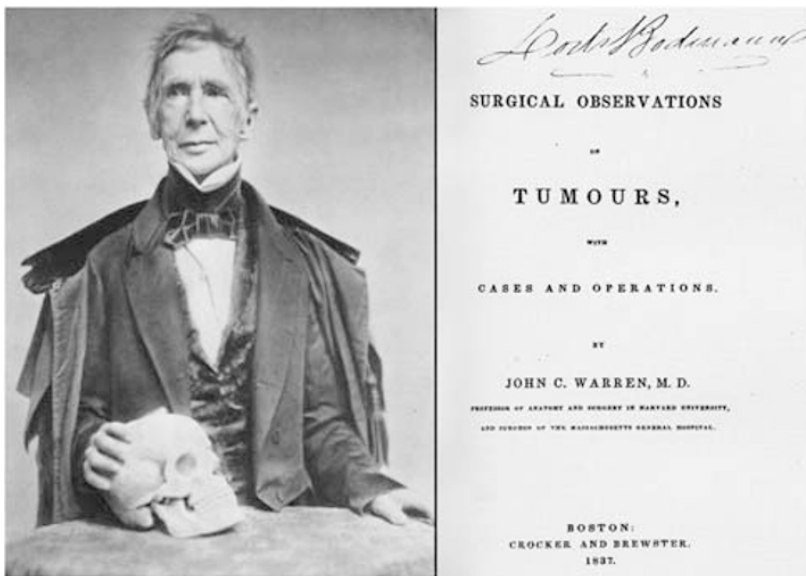

Figure 4 (Left) Dr John Collins Warren. (Right) Frontispiece of Dr Warren's 1837 book on tumors.

The museum still exists under the auspices of the Countway Library of HMS.

Although Warren's fame rests largely on his first public demonstration of ether anesthesia at the hospital on 16 October 1846, and his role in the founding of the hospital, two of his works are particularly notable in the context of the history of pathology. In 1809 he published a monograph entitled 'Cases of Organic Diseases of the Heart,' likely related to the interest his teacher, Corvisart, had in cardiac disease. More noteworthy from the perspective of pathology is his 1837 book 'Surgical Observations on Tumors, with Cases and Operations.' This book (Figure 4), dedicated to Sir Astley Cooper, is

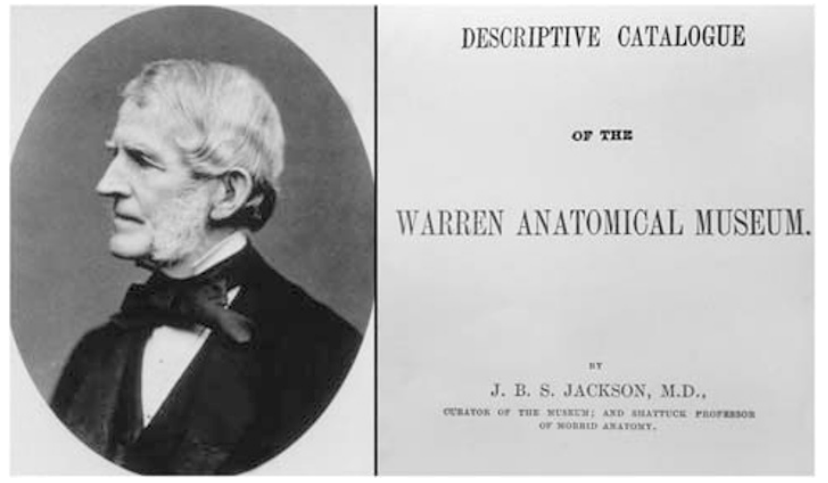

Figure 5 (Left) Dr John Barnard Swett Jackson. (Right) Cover of the catalogue of Warren Anatomical Museum prepared by Dr Jackson (1870).

607 pages long and has 16 plates, many in color. There are 14 chapters covering various subtypes of neoplasia and a final short section entitled 'Distinguishing Characters of the Most Common Tumors.' The coverage of gross aspects of pathology is impressive.

Although gross pathology had been a major interest of John Collins Warren, he was primarily a surgeon and it almost certainly did not consume as much of his time as it did for Dr John Barnard Swett Jackson (1806-1879) (Figure 5). ${ }^{6}$ Jackson was also a member of a medical family, being a nephew of the aforementioned Dr James Jackson. As JBS Jackson's father died when he was less than a year old, his uncle probably filled a paternal role for 
him. From 1829 to 1831, Jackson studied in Paris (with Dupuytren, Roux and Lisfranc), Edinburgh (with Syme) and London (with Bright, Addison and Hodgkin). Upon his return to Boston in 1831, he had a limited general practice, devoting most of his time to pathology at the MGH and HMS. He was a great collector of specimens, first for the 'Cabinet of the Society for Medical Improvement' and from 1847 as Curator for the Warren Anatomical Museum (Figure 5), when this museum was inaugurated after the donation of specimens from the collection of Dr JC Warren to the 'Cabinet'. In 1854 he became the first Shattuck Professor of Morbid Anatomy at HMS (and thereby the first professor of pathology in the United States) when his friend, George Cheyne Shattuck, Hersey Professor of the Theory and Practice of Physic, donated $\$ 14,000$ to endow the professorship.

\section{The start of microscopy at the MGH: Oliver Wendell Holmes, John Bacon and Calvin Ellis}

Despite the introduction of the microscope into pathology in the mid-nineteenth century, Jackson preferred gross pathology. In 1847, the MGH trustees voted that 'the admitting physician be authorized to purchase one of Oberhauser's microscopes at a cost not exceeding fifty dollars' with the stipulation that one of his duties was to 'examine microscopically and analyze all growths, tumors and diseased parts that may be removed from patients by operation or otherwise.' Jackson, however, restricted his pathological observations to gross findings. Oliver Wendell Holmes wrote in his eulogy of Jackson ${ }^{6}$ 'what he knew he knew thoroughly but he never pretended to have the slightest knowledge beyond what his honest naked eye could tell him... his look penetrated like an exploring needle, and many a tympanitic fancy of careless observers has collapsed under its searching scrutiny.' Jackson prepared detailed catalogs of the initial collection he oversaw in 1847 and then for that of the Warren Museum in 1870 (Figure 5). He is credited with recognizing that decidua was derived from normal tissue, a new concept at the time.

A famous physician at the MGH at this time was the eminent literary figure $\mathrm{Dr}$ Oliver Wendell Holmes (Figure 6), who was officially affiliated with the hospital from 1840 to 1849 . Holmes made an important contribution in 1843 when he published an essay on the contagiousness of puerperal fever. ${ }^{7}$ This was a revolutionary concept at the time and was met with hostility from many leading obstetricians; it was only the work of Semmelweis a few years later that led to the acceptance of this concept. It has been stated in a number of sources that Holmes' contribution on the etiology of puerperal fever was not more publicized because it appeared in an 'obscure journal' that did not last long. It is pleasing from the historical perspective

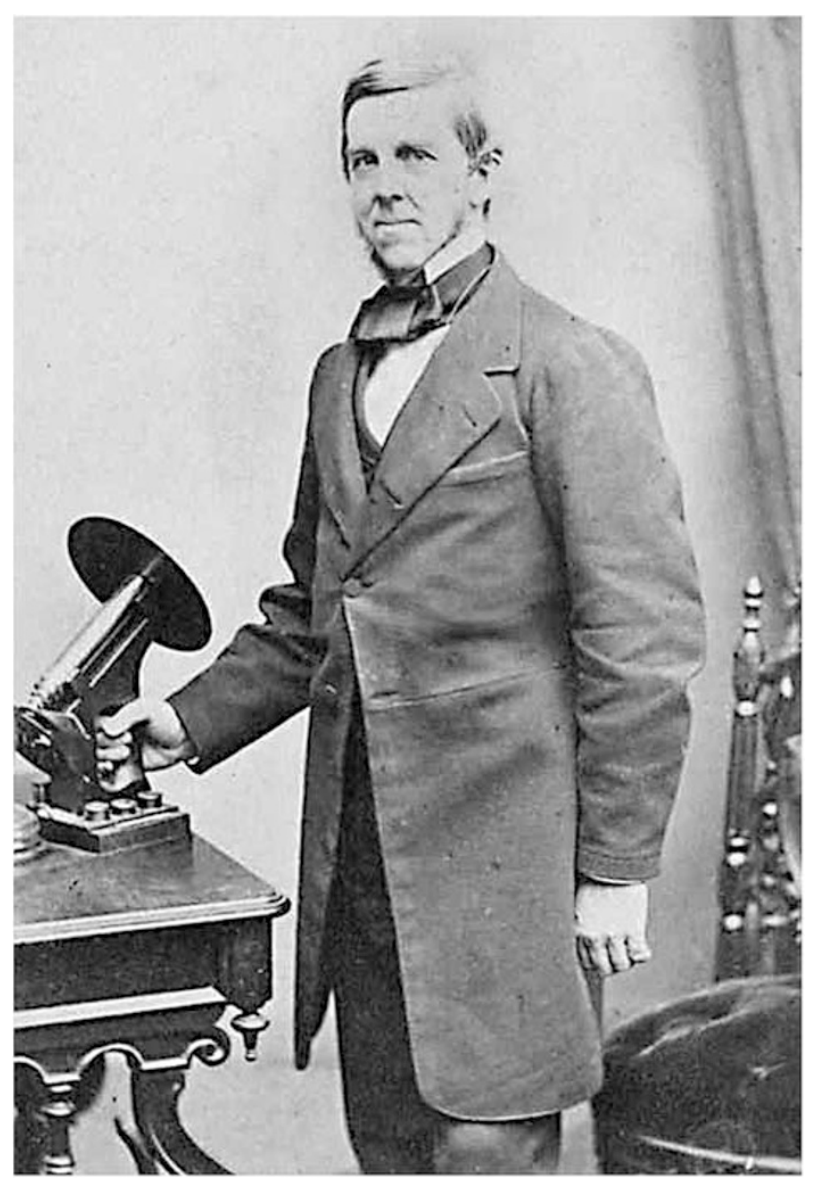

Figure 6 Dr Oliver Wendell Holmes, with early microscope (courtesy of the Boston Medical Library in the Francis A. Countway Library of Medicine).

that 100 years after his contribution there was a Centennial celebration of it at the New York Academy of Medicine and a tribute to Dr Holmes presented there by $\mathrm{Dr}$ Reginald Fitz (son of Dr Reginald Heber Fitz, see below) was published. ${ }^{8}$ In addition to his literary prowess, Holmes is usually given credit for the introduction of the microscope at HMS. As HMS was adjacent to the MGH on North Grove Street by 1847 (Figure 2), it is likely that his introduction of the microscope at HMS had an impact on its introduction at the hospital around that time. Given the hospital's decision to purchase a microscope as early as 1847, one wonders if Holmes had a role in lobbying for its purchase; however, we have been unable to find evidence of such a connection. Interested readers can refer to an excellent essay focusing on Dr Holmes' work as teacher and microscopist. ${ }^{9}$ Brief note should also be made that another important branch of medicine, anesthesiology, owes its very name to Dr Holmes inasmuch as he is credited with introducing the word 'anesthesia'.

The first person to take up microscopy officially at the MGH was Dr John Bacon Jr (Figure 7), who held the new position of Chemist and Microscopist from 1851 to 1855 and then the position of Chemist 


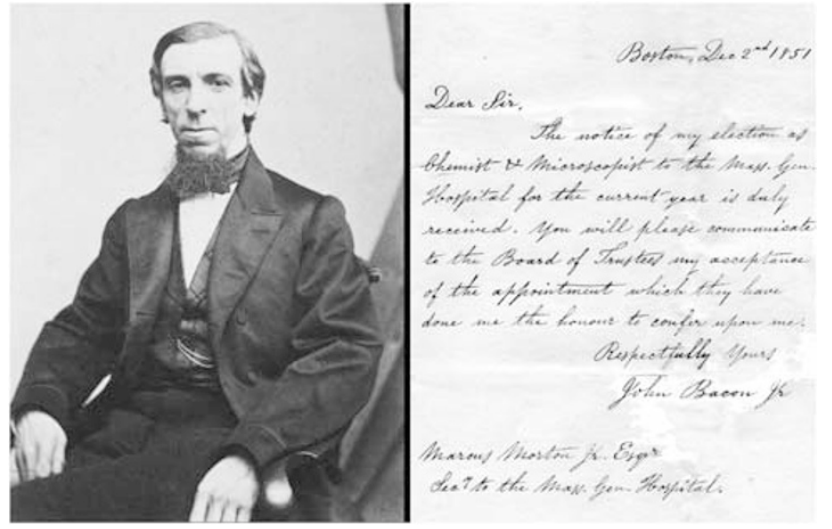

Figure 7 (Left) Dr John Bacon Jr (Harvard University Archives, call \# HUP Bacon, John ${ }^{1}$ ). (Right) Acceptance letter from Dr Bacon to the MGH Trustees, 1851: 'Dear Sir, The notice of my election as Chemist \& Microscopist to the Mass. Gen. Hospital for the current year is duly received. You will please communicate to the Board of Trustees my acceptance of the appointment which they have done me the honor to confer upon me. Respectfully yours, John Bacon Jr.'

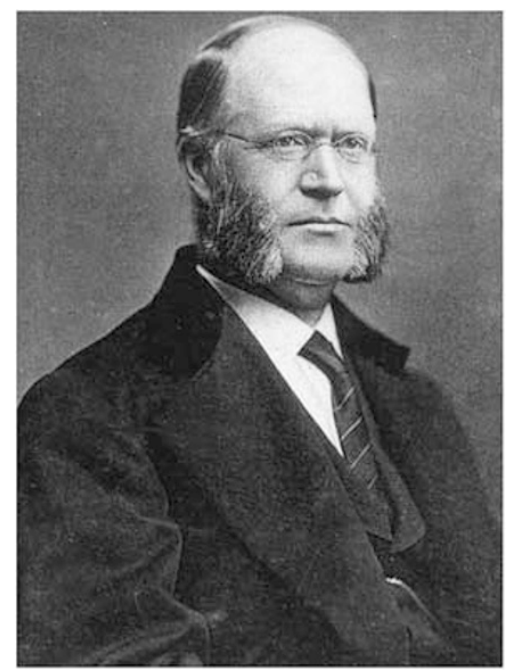

Figure 8 Dr Calvin Ellis.

from 1855 to 1863. Bacon's interest in chemistry was an early one, since he taught chemistry and toxicology to medical students and his recommendation in 1855 to separate the position of Chemist from that of Microscopist presumably related to the increase in clinical chemistry responsibilities. Nonetheless, he was an avid microscopist but apparently in relation to clinical fluid examination rather than in analysis of anatomical specimens; an obituary in a local paper remarked that 'He took especial delight in microscopy.'

Dr Calvin Ellis (1826-1883) (Figure 8) took over the role of Microscopist at the MGH after Dr Bacon, and held the titles of Shattuck Professor of Pathological Anatomy, Curator of the Pathological Cabinet and Microscopist for the hospital from 1855 to 1865 . He had studied medicine and pathology in Vienna, France and Germany. Upon his return he became Assistant to JBS Jackson. He was the first

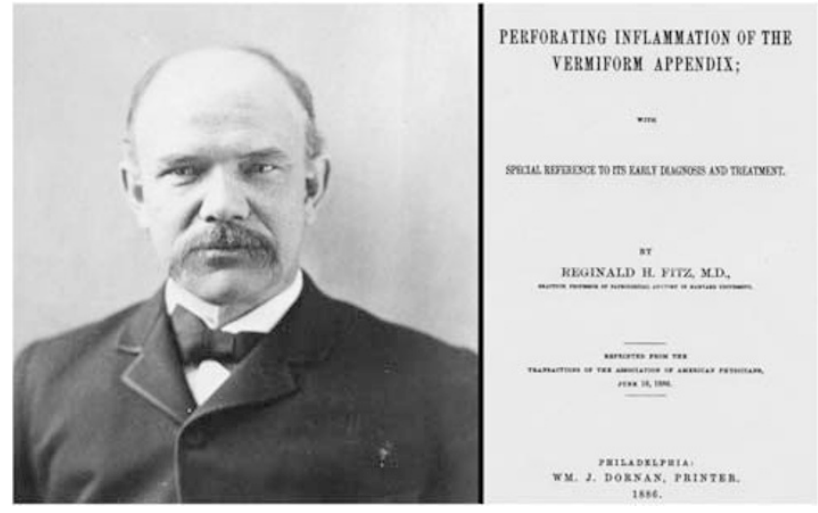

Figure 9 (Left) Dr Reginald Heber Fitz. (Right) Frontispiece of Dr Fitz's paper on appendicitis.

MGH physician to use the microscope in evaluating anatomical specimens. He published over 40 papers and won the Boylston prize in 1860 for his essay on 'Tubercle', considered in one remembrance as the best paper on the subject prior to Koch's discovery of the bacillus. ${ }^{10}$ Dr Ellis was appointed the Jackson Professor of Clinical Medicine in 1866 and served in that capacity until 1869 when he became Dean of HMS. In the latter capacity he cooperated with Harvard President Charles Eliot in the latter's sweeping reform of medical education at HMS. According to Eliot, 'he actively furthered all the many improvements made by the Faculty during his long term of service, and the changes made in 187071 could not have been effected without his (Ellis') support-a support which was as sturdy and strong as it was indispensable'.

\section{The first 'pathologist' at the MGH: Reginald Heber Fitz}

Dr Reginald Heber Fitz (1843-1918) (Figure 9) succeeded Dr Ellis as Microscopist and Curator of the Pathological Cabinet at the MGH in 1871. ${ }^{11}$ During his time as a microscopist, in 1874, the first significant pathology facilities were built at the MGH, on Allen Street, where they remained through 1956 when the Warren Building opened. He was the first physician to be designated Pathologist at the hospital. Fitz's first love had been business, but after a brief time working in a copper mine in Michigan, he realized his true vocation vowing to 'become an honorable practitioner respected by my brethren in the profession.' He graduated from HMS in 1868 and then trained with Rokitansky, Virchow and the latter's student, Orth, in Germany. When Orth's book 'A Compend of Diagnosis in Pathological Anatomy' was translated into English by Frederick Shattuck and George Sabine, Fitz had a role in enhancing the English translation by being the reviser of the work. Fitz has been remembered 'as using the methodical German technique at autopsies, which was a revelation to house officers' 
and was noted for his clear-cut concise description of pathological changes. Fitz became the head of the HMS Pathology Department in 1879 (upon the death of Dr JBS Jackson), as the third Shattuck Professor. He made outstanding contributions, the most notable being in 1886 in his paper entitled 'Perforating inflammation of the vermiform appendix with special reference to its early diagnosis and treatment $^{12}$ (Figure 9). He showed that acute inflammation, abscess formation and bowel perforation in the cecal region were almost always secondary to a disease he designated 'appendicitis.' Although others had made contributions concerning this condition previously, Fitz's study was more significant in that it included a plea for appendectomy as the appropriate treatment. This was contrary to the generally prevailing opinion that the acute inflammatory condition in these cases arose in the cecum (typhlitis or perityphlitis) with secondary involvement of the appendix. The late Dr William B Ober, a pathologist and noted medical historian, stated that a case can be made for Fitz's investigation of appendicitis as marking the beginning of surgical pathology in North America. ${ }^{13}$

Another major contribution by Dr Fitz was his 1889 paper on acute pancreatitis. ${ }^{14}$ He first delivered his findings when he gave the Middleton-Goldsmith lecture to the New York Pathological Society on 16 February 1889, and his findings were published shortly afterwards in the Boston Medical and Surgical Journal. In his report Fitz reviews in detail the literature on the pancreas and many of its disorders. He then notes that his own interest was stimulated by an autopsy he had performed in 1876 of a patient who died of pancreatitis. He then studied further pancreatic specimens, getting significant help from Dr William Fiske Whitney (see below). Dr Fitz discusses pancreatic hemorrhage, the association of hemorrhage with acute pancreatitis, pancreatitis occurring without hemorrhage and the relation of acute pancreatitis to fat necrosis. Dr HR Viets, when he discussed what he thought were the 20 most significant papers published in the first 150 years of the New England Journal of Medicine, stated that 'The report by Fitz is a model of completeness, putting the disease in a new setting, with an authority that could come only from long continued study of the basic pathology'. ${ }^{15}$ In 1892, Dr Fitz relinquished the chair of pathology to become the Hersey Professor of Theory and Practice of Physic.

During the busy years of the 1880s, when Dr Fitz was doing research and reporting his findings widely, he was helped by Dr William Whitworth Gannett. Dr Gannett was appointed Assistant in Pathology in 1882 and had a liking for autopsy pathology, humorously leading to him being known as 'Buzz' because, as remarked in an obituary, ${ }^{16}$ 'like the buzzard, he was noted for his fondness for post-mortem material.' Dr Gannett went on to serve as a pathologist for a number of hospitals in the Boston area.

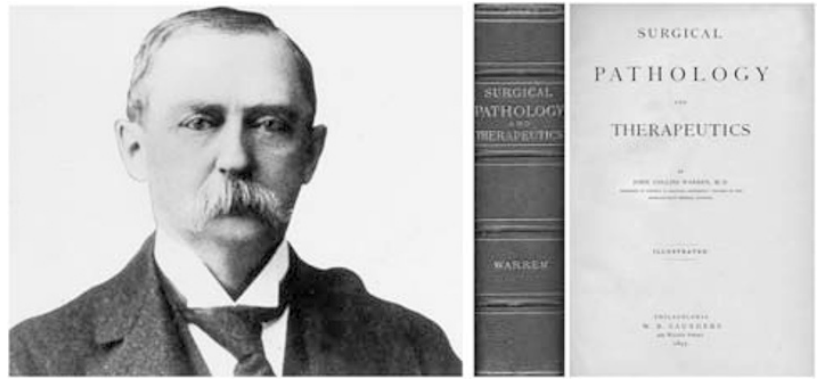

Figure 10 (Left) Dr J Collins Warren. (Right) Spine and frontispiece of Dr Warren's 1895 book.

\section{The development of surgical pathology: J. Collins Warren}

The development of surgical pathology at the hospital can be traced most clearly to another distinguished member of the Warren family: John Collins Warren (1842-1927) (Figure 10), grandson of the first John Collins Warren. He styled his name J Collins Warren to distinguish himself from his grandfather (generally styled as John C Warren) and appears to have been referred to as 'Coll' by close friends. After graduation from HMS in 1866, J Collins Warren studied in Vienna in Rokitansky's laboratory and under Billroth, the famed surgeon who had a major interest in pathology and wrote an influential text on the topic. Warren himself greatly credited the time he spent studying histological techniques and microscopy with Alfred Biesiadecki (a protégé of Rokitansky). ${ }^{17} \mathrm{He}$ also studied in Berlin under Cohnheim (remembering later this experience with strong positive feelings) and in Paris under Ranvier and Cornil, and completed his European travels in Glasgow with Joseph Lister, whose concepts he accepted. He fought vigorously to have them instituted at the MGH, against strong opposition. Notably the last chapter of his book (see below) is entitled 'Aseptic and Antiseptic Surgery'.

In 1870, back at the MGH, Warren began to record pathologic observations in a private ledger entitled 'Microscopic Examination of Tumors.' The ledger was based on his own specimens as well as those submitted to him by other surgeons; the diagnoses were copied into the patients' records by the surgical house pupils (residents). Such diagnoses constituted early examples of anatomical pathology diagnoses at the hospital.

Warren made important contributions to the pathology literature. His first pathology paper, written in Europe, was on the development of keloids. After his return to Boston, he won the Boylston prize in 1872 for his paper on 'The Anatomy and Development of Rodent Ulcer,' what is now known as basal cell carcinoma being poorly understood at that time. Warren authored a book 'Surgical Pathology and Therapeutics,' published in $1895^{18}$ (Figure 10). The second sentence of the preface states that 'no young practitioner can be 
considered thoroughly equipped for surgical work who is not both a good pathologist and bacteriologist.' The book, which runs to 810 pages, is based largely on gross observations made in the operating room, but it also includes a microscopic classification of breast tumors with drawings reflecting his particular interest in breast disease. There is also significant coverage of bacteriology. Indeed the majority of the illustrations are related to that area rather than anatomic pathology, hence according to the usage of today the title of his book is a little misleading. His interest in infections likely dates back to his service in 1864 as an assistant surgeon in the Civil War. He and several others of his medical school class volunteered for service after a call for volunteers by the governor of Massachusetts. Interestingly, in his reminiscences ${ }^{17}$ Dr Warren makes essentially no comment on his work on the book. He does mention working in the North Grove Street medical school building with Dr Fitz and others and the editor of his reminiscences notes, in reference to his microscopic work, that 'apparently his services in this regard supplemented those of a duly appointed hospital microscopist, then Calvin Ellis.' Dr Warren's publications on breast disease include one entitled 'The Diagnosis and Treatment of Cancer of the Breast' published in $1889^{19}$ and a paper 16 years later based on a study of 758 cases. ${ }^{20}$

Dr Warren was a pioneer of the use of the needle biopsy in evaluating breast disease and in his book comments 'the diagnosis of cancer of the breast often presents great difficulties...the use of the Mixter punch (a fine cannula sharpened on the inner edge) is most valuable in such cases, and in fact, in all doubtful cases of cancer. The operation, when performed with cocaine injections, is painless and harmless, and secures a specimen amply sufficient for microscopic diagnosis.' At that time, the suggestion that one would biopsy a breast tumor in advance of a resection was controversial. The Mixter punch cannula, invented by an innovative surgical associate of Warren, Samuel Jason Mixter, may have been the first instrument devised for needle biopsy of tumors. Warren also has a claim to priority in utilization of frozen section in tumor diagnosis, having written in 1889 that specimens were sometimes examined immediately 'with the freezing microtome;' this was 6 years before the more detailed report of frozen section technique by the Hopkins gynecologist pathologist, Thomas S Cullen, ${ }^{21}$ who is generally credited with devising the technique. ${ }^{22}$ Warren worked at a time when German investigators dominated pathology but it is noteworthy that one medical historian considered him one of the five most significant American contributors to the growth of clinical microscopy in the United States in the nineteenth century. ${ }^{23}$ Dr Warren also had a major role in the move of HMS to its new (and current) location, on Longwood Avenue in $1906^{24}$ and was the first Moseley Professor of Surgery at the medical school.

Given the legacy of the Warren family to the hospital and the study of pathology, it is fitting that their name is commemorated in the name of the building that houses a significant part of the department to this day (Figure 11). The new building dates to the mid-1950s, and was built in part to house the new pathology laboratories. Originally dubbed the Medical Science Building, it soon was named the 'Warren Building' to honor this remarkable family.

\section{The first 'surgical pathologist': William Fiske Whitney}

From 1888, the hospital was well served by another illustrious figure, Dr William Fiske Whitney (18501921), ${ }^{25,26}$ whose career saw the movement of

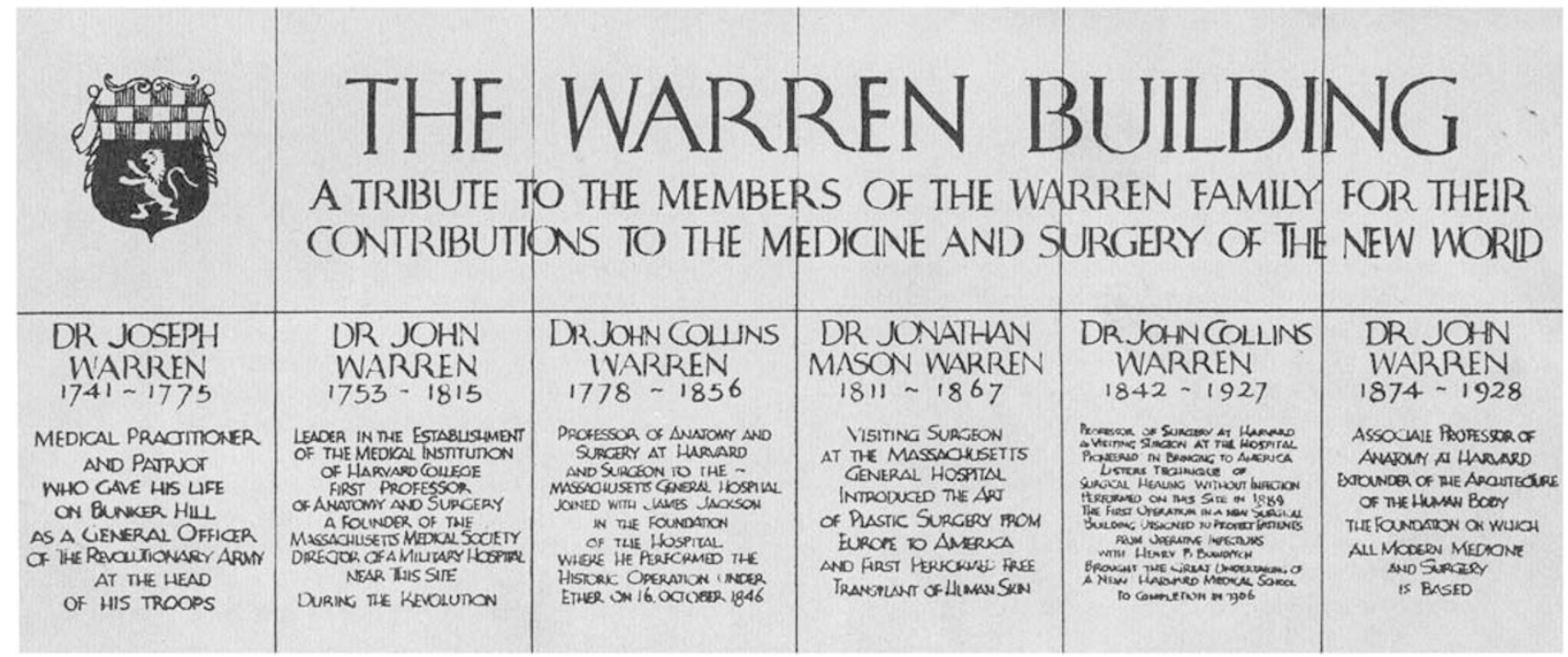

Figure 11 Commemorative marble wall honoring the contributions of the Warren family to Massachusetts General Hospital and Harvard Medical School, Lobby of Warren Building. 


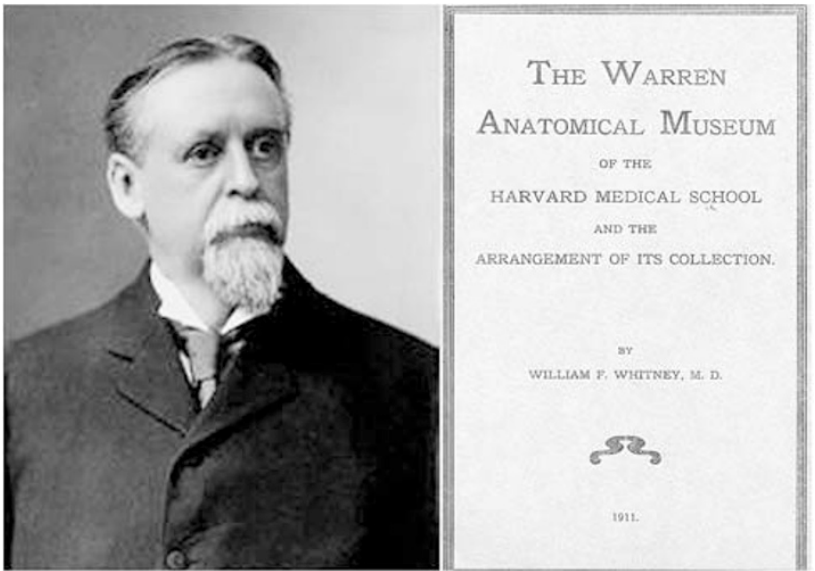

Figure 12 (Left) Dr William Fiske Whitney. (Right) Cover of the booklet on The Warren Anatomical Museum prepared by $\mathrm{Dr}$ Whitney (1911).

diagnostic pathology from the realm of the surgeon to the hand of the specialist pathologist. Dr Whitney (Figure 12) was an HMS graduate and, after serving as a house officer at the MGH, studied in Berlin, Munich and Strasburg. His early interests were in anatomy, which served him well when he turned his attention to pathology. In 1879 he became Curator of the Warren Anatomical Museum (Figure 12), serving as such for a remarkable 42 years, indeed until his death. ${ }^{27} \mathrm{He}$ was appointed pathologist to the MGH in 1888 and served the hospital in that capacity until his retirement in 1916. From 1901 to 1916, he carried the specific title of Surgical Pathologist, the first to do so at the MGH. Dr Whitney had a broad diversity of interests, ranging from conventional diagnostic pathology to forensic pathology (he testified frequently in court on murder cases) to infectious disease (being for a decade Professor of Parasitic Diseases of the Veterinary School of Harvard University). He was also noted to have 'familiarity with more than half a dozen different languages.' In a tribute to Dr Whitney after his death, Drs J Collins Warren and Samuel J Mixter noted his 'wonderful skill and quick diagnosis and knack in the examination of fresh specimens' ${ }^{25}$ In their obituary, they provided an early description of the importance of a great surgical pathologist: 'The hesitating surgeon, knife in hand, uncertain whether to do a trifling operation or one terribly mutilating and severe, could always depend on the decision of his mastermind and vast experience, and a great number of men and women today owe their intact bodies, or their lives, to his quietly spoken opinion'.

Dr Whitney should be considered a major transitional figure in the practice of pathology at the hospital. He was the first person to spend his career at MGH oriented firmly around the practice of pathology, rather than practicing pathology parttime while serving as a physician or surgeon. Second, he set the stage for the burgeoning of surgical pathology in the years after the formation of the Pathology department in 1896. One of his trainees was Dr Harry Fairbanks Hartwell who, after 7 years as an orthopedic surgeon at MGH, was appointed Assistant Surgical Pathologist in 1911 and was formally appointed as Surgical Pathologist upon the retirement of Dr Whitney in 1916. He held the position of Surgical Pathologist through 1938. It is remarkable that Drs Whitney and Hartwell served as the surgical pathologists for the hospital for half a century (1888-1938), extending from the earliest incarnations of the field to its near-modern practice.

\section{The end of the beginning: William $T$ Councilman and James Homer Wright}

William T Councilman arrived at HMS to succeed Fitz as Shattuck Professor of Pathological Anatomy in 1892. This augured a new era of pathology in Boston, reflecting the changing times. ${ }^{28}$ Although he never worked at the MGH, he had a seminal role in the development of pathology there because of his recommendations in the early 1890s to the MGH Trustees to establish a Pathology laboratory and to hire a full-time pathologist to oversee all of the laboratories (ie, bacteriology, autopsy, etc, as well as surgical pathology), and through the recruitment to MGH of one of his students, James Homer Wright, to the position. Dr Wright had been working at the Boston City Hospital since 1893. He assumed this position on 13 March 1896 when he was still only 26 years old. ${ }^{2}$ The new MGH laboratory was officially opened on 16 October 1896, the 50th anniversary of the first public demonstration of the use of ether anesthesia, appropriately linking Wright's appointment with the first John Collins Warren. A new era began but the contributions of the early pioneers are clearly deserving of their own place in the annals of pathology.

\section{Disclosure/conflict of interest}

The authors declare no conflict of interest.

\section{Acknowledgements}

This essay would have been impossible for us to write without the material donated to us by Dr Robert E Scully and the late Dr Austin L Vickery Jr, some of which was a result of their own research. ${ }^{3}$ Furthermore, during the writing of this essay we were fortunate to be able to call upon Dr Scully to answer a number of questions and we are grateful to him for sharing information based on his vast knowledge of the history of pathology in general and of the Massachusetts General Hospital. Dominic Hall (Warren Anatomical Museum, Center for the History of Medicine, Countway Library of Medicine, 
Harvard Medical School), Jack Eckert (Center for the History of Medicine, Countway Library of Medicine, Harvard Medical School), Martha Stone (Treadwell Library, Massachusetts General Hospital), all provided great assistance for this essay and we are indebted to all of them.

\section{References}

1 Louis DN, Young RH (eds). Keen Minds to Explore the Dark Continents of Disease. A History of the Pathology Services at the Massachusetts General Hospital. Massachusetts General Hospital: Boston, 2011.

2 Lee RE, Young RH, Castleman B. James Homer Wright: a biography of the enigmatic creator of the Wright Stain on the occasion of its centennial. Am J Surg Pathol 2002;26:88-96.

3 Scully RE, Vickery Jr AL. Surgical Pathology at the Hospitals of HMS. In: Rosai J (ed), Guiding the Surgeon's Hand. The History of American Surgical Pathology. American Registry of Pathology: Washington, DC, 1997.

4 Bull W, Bull M. Something in the Ether. A Bicentennial History of Massachusetts General Hospital 1811 to 2011. Memoirs Unlimited: Beverly, MA, 2011.

5 Traux R. The Doctors Warren of Boston. First Family of Surgery. Houghton Mifflin: Boston, 1968.

6 Holmes OW. John Barnard Swett Jackson (Eulogy). Boston Med Surg J 1897;100:63-66.

7 Holmes OW. The contagiousness of puerperal fever. N Engl Quart J Med 1843;1:503-530.

8 Fitz R. My Dr Oliver Wendell Holmes. Bull NY Acad Med 1943;19:540-554.

9 Hunt TE, Hunt EA. Dr Oliver Wendell Holmes: teacher and microscopist. Alabama J Med Sci 1966;76:90.

10 Harrington TF, Mumford JG. The Harvard Medical School. A History, Narrative and Documentary; 1782-1905. Lewis Publishing: New York, 1905.

11 Cheever D, (ed) Three notable teachers at Harvard Medical School (R. Fitz, M. Richardson, and J.C. Warren) Harvard Medical Alumni Association Bulletin, New Series, no. 6, July 1908.

12 Fitz RH. Perforating inflammation of the vermiform appendix. With special reference to its early diagnosis and treatment. Trans Assoc Am Phys 1886;I: 107-144.
13 Ober WB. American pathology in the 19th century: notes for the definition of a specialty. Bull NY Acad Med 1976;52:326-347.

14 Fitz RH. Acute pancreatitis. A consideration of pancreatic hemorrhage, hemorrhagic, suppurative, and gangrenous pancreatitis and of disseminated fat necrosis. Boston Med Surg J 1889;120:181-187, 205-207, 229-235.

15 Veits HR. A score of significant papers published in the journal during the last hundred and fifty years. N. Engl J Med 1962;266:23-28.

16 Farlow JW. Obituary. William Whitworth Gannett, MD 1853-1929. N Engl J Med 1929;200:1177-1180.

17 Churchill ED, (ed) To Work in the Vineyards of Surgery. The Reminiscences of J. Collins Warren (1842-1927). Harvard University Press: Cambridge, MA, 1958.

18 Warren JC. Surgical Pathology and Therapeutics. WB Saunders: Philadelphia, 1895.

19 Warren JC. The diagnosis and treatment of cancer of the breast. Boston Med Surg J 1889;190:349-363.

20 Warren JC. The surgeon and the pathologist. A plea for reciprocity as illustrated by the classification and treatment of benign tumors of the breast. JAMA 1905;45:149-165.

21 Young RH. History of Gynecological Pathology. I Dr Thomas S Cullen. Int J Gynecol Pathol 1996;15: 181-186.

22 Wright Jr JR. William Osler Medal Essay: the development of the frozen section technique, the evaluation of surgical biopsy and the origins of surgical pathology. Bull Hist Med 1985;59:295-326.

23 Malkin HM. Comparison of the use of the microscope in pathology in Germany and the United States during the nineteenth century. Ann Diagn Pathol 1998;2: 79-88.

24 Churchill ED. The Harvard Medical School, 19061956. N. Engl J Med 1956;255:1035-1041.

25 Warren JC, Mixter SJ. A tribute to a pioneer in modern pathology. Bost Med Surg J 1922;186:113-115.

26 Abbott M. William Fiske Whitney (1850-1921). Bull No. VIII Int Assoc Med Museums J Tech Methods $1922 ; 1-2$.

27 Whitney WF. The Warren Anatomical Museum of Harvard Medical School and the Arrangement of its Collection 1911.

28 Beecher HK, Altschule MD. Medicine at Harvard. The first 300 years. University Press of New England: Hanover, NH, 1977, pp 587. 